\title{
Client Satisfaction in the Quality of Post Abortion Care Among Women Attending in Public Health Facility of Gambella, Ethiopia
}

\author{
Ephrem Teshome ${ }^{1}$, Girmay Adhena ${ }^{2, *}$ \\ ${ }^{1}$ Department of Public Health, Gambella University, Gambella, Ethiopia \\ ${ }^{2}$ Department of Reproductive Health, International Medical Corps, Gambella, Ethiopia
}

Email address:

girmayrh@gmail.com (G. Adhena)

${ }^{*}$ Corresponding author

\section{To cite this article:}

Ephrem Teshome, Girmay Adhena. Client Satisfaction in the Quality of Post Abortion Care Among Women Attending in Public Health Facility of Gambella, Ethiopia. Journal of Gynecology and Obstetrics. Vol. 9, No. 3, 2021, pp. 66-74. doi: 10.11648/j.jgo.20210903.13

Received: March 29, 2021; Accepted: May 28, 2021; Published: June 16, 2021

\begin{abstract}
Background: The quality of post-abortion care services is essential to improve the health of women who experience complications from abortion. Abortion and its complication is the most common cause of maternal death in Africa, particularly in Ethiopia. Despite this fact, little attention is given to the quality of post-abortion care. This study was aimed to assess client satisfaction in the quality of post-abortion care among women in the public health facility of Gambella, Ethiopia. Methods: A facility-based crossectional study was done among 194 participants. A consecutive sampling technique was used to select the study participants. A structured, pretested, and interviewer-administered questioner was used to collecting the data. Binary and multivariable logistic regression analysis was done to identify associated factors. An adjusted odds ratio with $95 \%$ CI was used to estimate the direction and strength of the association. Variable with a p-value $<0.05$ was considered as statistically significant. Results: About $169(87.1 \%, 95 \%$ CI: $(82,91.8))$ participants were satisfied in the quality of post abortion care (PAC) services. Unwanted pregnancy [AOR $=1.8,95 \%$ CI: $(1.17,10.9)]$, history of abortion $[2.1,95 \%$ CI: $(1.6$, 13.8)], assisted by physician [AOR $=3.995 \% \mathrm{CI}:(1.6,8.6)]$, treated politely and respectfully [AOR=6.3, $95 \% \mathrm{CI}:(1.82,22.2)$ ], the provider adress all questions raised by the client $[\mathrm{AOR}=5.1,95 \% \mathrm{CI}$ : $(1.9,14.5)]$ were significantly associated factors. Conclusion: The majority of the study participants were satisfied with the quality of post-abortion care services. Enhancing patient care in the facility, strengthening awareness of family planning services, and addressing the questions of the clients in a respected manner are important measures that increase client satisfaction.
\end{abstract}

Keywords: Client Satisfaction, Post Abortion Care, Quality, Gambella, Ethiopia

\section{Introduction}

Patient satisfaction is an important and commonly used indicator for measuring the quality of health care as it affects clinical outcomes, patient retention, and medical malpractice claims [1]. The quality of reproductive health care is critical in determining whether the service meets clients' expectations or not, the choice of services, and the constellation of related services [2]. Quality of post-abortion care (PAC) services are essential to improve the health of women who experience complications from abortion [3]. It is a life-saving intervention that reduces the risks of mortality and morbidity [4].
Comprehensive post-abortion care was identified as an important intervention to treat complications resulting from miscarriage and unsafe abortion, reduce the incidence of repeat unplanned pregnancy, and decrease the incidence of repeat abortion, and achieve the satisfaction of clients [5].

Abortion is one of the leading causes of maternal mortality and morbidity worldwide [6]. Evidence showed that above 20 million unsafe induced abortions occur worldwide each year and result in up to $13 \%$ of all maternal deaths even though, the majority of these deaths are easily preventable [7, 8]. Among 46 million abortions that occur in the world each year to end un-desired pregnancy, nearly half of them take place in countries where highly restrictive abortion laws 
often drive women to seek unsafe abortion with the highest magnitude in developing countries [9].

An estimated 30,000 deaths due to abortion and related complications have been reported in Africa which is over $40 \%$ of the total deaths [3]. In sub-Saharan Africa, up to 50 percent of gynecological beds are occupied by patients with abortion complications. World Health Organization estimated that $18 \%$ of maternal deaths in East Africa as compared to $13 \%$ globally were caused by unsafe abortions [10].

Ethiopia is one of the developing countries with a contraceptive prevalence of less than $15 \%$ and the highest maternal mortality rate estimated to be 412 per 100,000 live births [6]. The main contributing factors for this high death toll include unsafe abortion among others. Evidence in Ethiopia indicates that unsafe abortion accounts for up to 25 to 35 percent of maternal deaths [11].

A high proportion of women who undergo unsafe induced abortion require medical care, however, access to quality PAC remains a challenge, especially among low-income countries [12]. Induced abortion is considered illegal in many low-income countries, and women often fail to seek intervention owing to a fear of legal repercussions. In countries where the provision of abortion is restricted or low quality or inaccessible, women often resort to unsafe methods that result in complications, long-term health problems [13].

Evidence reviled that after a pregnancy loss, women were not given family planning information or supplies to space their next pregnancy [14]. Restrictive national laws, lack of access to safe abortion, and lack of quality post-abortion cars have led to the premature death of millions of mothers $[6,15]$. An estimated 5.2 million women seeking treatment for short and long-term morbidities including uterine perforation, chronic pelvic pain, and secondary infertility $[14,16]$. To reduce the risk of long-term illness, disability, and death to women presenting with complications of incomplete abortion, healthcare systems must provide easily accessible, highquality comprehensive post-abortion care (PAC) at all health care facilities that provide abortion service [17].

Intervention is not provided in time, stigma, cultural, socioeconomic, and religious factors to minimize any conversations on induced abortion [18]. Although complications from unsafe induced abortion can be lifethreatening, many women fail to seek PAC because they fear reprimand from medical personnel, whereas others do not seek care due to low income, and cultural practices, even among countries where PAC is highly subsidized [19].

The leading known cause of unsafe induced abortion is unintended pregnancy, which is associated with the unmet need for FP services [20]. Contraceptive interventions are therefore an important pathway to prevent unsafe induced abortions by reducing the risk of unwanted or mistimed pregnancies before and after induced abortion. The PAC Consortium model advocates the provision of FP counseling and services to increase contraceptive uptake and so reduce repeat unintended pregnancies and to succeed client satisfaction [21].
In Ethiopia, abortion is the common cause of maternal death. Assessing the patients' perspective provides evidence for the local and other program planners to provide quality services with the targets measured to the satisfaction of the clients. Studies in Ethiopia on the quality of PAC were limited in the study area. Thus, this study was aimed to assess client satisfaction in the quality of post-abortion service in Gambella, Ethiopia.

\section{Methods}

\subsection{Study Area and Period}

This study was conducted in Gambella Town, South-west Ethiopia. Gambella is located 766 kilometers away from Addis Ababa, the capital city of Ethiopia. The town has a total population of 59,462 out of this, $30,326(51 \%)$ were females, and 29,136 (49\%) were males [22]. The study was conducted from June -July 2019.

\subsection{Study Design}

An institutional-based cross-sectional study was used.

\subsection{Population}

All women who were seeking abortion care in the public health facility of Gambella Town were the source population. All women who received abortion care in public health facilities during the data collection period consisted of the study population. Women who were unable to respond to the interview due to severe illness were excluded.

\subsection{Sample Size Determination and Sampling Procedures}

The sample size was calculated by using a single population proportion formula $\left(n=(Z \alpha / 2)^{2} \mathrm{P}(1-\mathrm{P}) / \mathrm{d}^{2}\right)$ where, $\mathrm{Z}$ is the $95 \%$ of confidence level, $5 \%$ margin of error (d), and $83.5 \%$ prevalence of client satisfaction in the quality of PAC from a previous study done in Guragea [23]. by inserting the number in the formula then it results as $n=206$. By adding $10 \%$ of the non-response rate, the final sample size (n) for the first objective was $206+(10 \% * 206)=226$, so the final sample size used for this study was 226 . For the sampling procedure, all public hospitals in Gambella town were taken. The number of abortion that was done in the public hospitals were taken within two months before the actual data collection begins. After estimating the number of women who attended abortion care, then the population proportional allocation to the sample size was done. Finally, participants were selected using a consecutive sampling technique until the required sample size was met.

\subsection{Data Collection Tool and Procedure}

A standardized WHO questioner was used for assessing client satisfaction in the quality of PAC [7, 24]. The questioner includes socio-demographic characteristics, health facility, Reproductive Health, and other related characteristics. It was translated to local languages (Amharic, Nure, and Agnuak) by 
language experts (person) then it was back-translated to English by another person to check the consistency. Pretest was done on $5 \%$ (10 samples) of the sample size at Abebo health center, which is $20 \mathrm{~km}$ far away from the study site but the same socio-cultural characteristics with study population before one week of data collection period to check the validity of a questionnaire. Data were collected through a face-to-face interview by four midwives (degree holders). Two public health officers and the principal investigators supervised the data collection procedure. Two days of intensive training on data collection tool, ethical issue, and quality of data was given for data collectors and supervisors. Close follow-up was done by the supervisors and principal investigators through the data collection period. The collected data were cross-checked each day for consistency, and completeness.

\subsection{Operational Definitions}

Post-abortion clients: Were those who got abortion service and declared by the provider in charge as having an abortion regardless of the cause and type [23].

Client satisfaction in PAC: This was measured by the overall client's perception toward the PAC services they received. This consists of 4 Likert items (privacy, technical quality of provider, information provision, and cleanliness). Those who scored mean and above were categorized as satisfied and score below the mean categorized as unsatisfied [25].

\subsection{Data Processing and Analysis}

The data was first coded, entered, and cleaned using Epidata version 3.1 statistical software version and then exported into SPSS version 20 for analysis. Descriptive statistical analysis such as simple frequencies, measures of central tendency, and measure of variability was used to describe the characteristics of respondents. Then information was presented using frequencies, summary measures, tables, and figures. The bivariable analysis was carried out to see the association of each independent variable with the outcome variable. All Variables with a p-value $<0.25$ in the bivariable analysis were taken into the multivariable analysis model to control possible confounders. A Co-linearity test was carried out to see the correlation between independent variables using standard error. A Hosmer-Lemeshow and Omnibus test was done to test model goodness of fit. The multivariable analysis was performed in the binary logistic regression up on controlling for the possible confounding factors. The odds ratio with $95 \%$ CI was reported to show the strength and direction of the associations. Variable with a p-value less than 0.05 was declared as statistically significant.

Table 1. Background characteristics of participants in public health facility of Gambella town, South West Ethiopia, 2019 (N=194).

\begin{tabular}{|c|c|c|c|}
\hline Variables & Category & Frequency & Percent (\%) \\
\hline \multirow{3}{*}{ Age (year) } & $15-24$ & 67 & 34.5 \\
\hline & $25-34$ & 66 & 34.0 \\
\hline & $35-49$ & 61 & 31.4 \\
\hline \multirow{5}{*}{ Ethnicity } & Nuer & 51 & 26.3 \\
\hline & Agnhak & 30 & 15.5 \\
\hline & Mejenger & 20 & 10.3 \\
\hline & Oromo & 27 & 13.9 \\
\hline & Others & 35 & 18.0 \\
\hline \multirow{4}{*}{ Level of education } & No formal education & 14 & 7.2 \\
\hline & Primary school & 38 & 19.6 \\
\hline & Secondary school & 62 & 32.0 \\
\hline & Diploma and above & 59 & 30.4 \\
\hline \multirow{3}{*}{ Religion } & Orthodox & 74 & 38.1 \\
\hline & Muslim & 19 & 9.8 \\
\hline & Catholic & 27 & 13.9 \\
\hline \multirow{3}{*}{ Marital Status } & Married & 127 & 65.5 \\
\hline & Single & 33 & 17 \\
\hline & Divorced/Widowed/ & 34 & 17.5 \\
\hline \multirow{6}{*}{ Occupation } & Government employee & 46 & 23.7 \\
\hline & NGO employee & 27 & 13.9 \\
\hline & Private organization Employee & 31 & 16.0 \\
\hline & Self-dependent & 35 & 18.0 \\
\hline & No employment & 21 & 10.8 \\
\hline & Student & 34 & 17.5 \\
\hline
\end{tabular}

\subsection{Ethical Consideration}

Ethical clearance was secured from Mettu University College of Health and Medical Sciences Institutional Health Research Ethics Review Committee (IHRERC). The official letter was written from Mettu university to the Gambella health bureau and each public health facility. Informed, voluntary, written and signed consent was obtained from each head of the health facilities and each participant after clearly informing them about the purpose and risk of the study. Respondents were informed that participating in this study is up to the willingness. To assure the confidentiality of the study participants' information, the interview was conducted in a separate and calm room in each health facility. 


\section{Result}

\subsection{Background Characteristics Participants}

Among a total of 226 expected participants, about 194 of them were interviewed making a response rate of $86 \%$. The mean age of participants was $29.4(\mathrm{SD} \pm 8.7)$ years old. About $67(34.5 \%)$ participants were in the age group of 15-24. More than one-fourth, $51(26.3 \%)$ were Nuer in their ethnicity. The majority, $127(65.5 \%)$ of participants were married in their relationship status. Regarding educational level, about 59 $(30.4 \%)$ were diploma and above, $62(32 \%)$ were learned secondary school, and about $38(19.6 \%)$ were completed primary school. About 74 (38.1\%) were Orthodox in their religion and near to one-fourth, 46 (23.7\%) were government employed in their employment status (Table 1).

Reproductive health and other related characteristics of participants

About 63 (32.5\%) participants reported they had 3 times gravidity, one-fifth had three children, 117 (60.3\%) had a history of abortion, $119(61.3 \%)$ participants were wanted pregnancy. About 83 (42.8\%) of participants reported that the abortion was due to financial problems, half of the participants, $98(50.3 \%)$ had no plan for future pregnancy, $188(96.9 \%)$ reported the informed well about family planning use after abortion (Table 2).

Table 2. Reproductive health and other related characteristics among post-abortion clients in Public health facility, Gambella Town South West Ethiopia, June 2019-July 2019.

\begin{tabular}{|c|c|c|c|}
\hline Variables & Category & Frequency & Percent (\%) \\
\hline \multirow{4}{*}{ Gravidity } & One time & 28 & 14.4 \\
\hline & Two times & 44 & 22.7 \\
\hline & Three times & 63 & 32.5 \\
\hline & Four and Above & 59 & 30.4 \\
\hline \multirow{4}{*}{ Parity/Number of children } & No child & 48 & 24.7 \\
\hline & One child & 42 & 21.6 \\
\hline & Two child & 55 & 28.4 \\
\hline & Three child & 49 & 25.3 \\
\hline \multirow{3}{*}{ History of previous abortion } & Yes & 117 & 60.3 \\
\hline & No & 77 & 39.7 \\
\hline & No abortion history & 77 & 39.7 \\
\hline \multirow[t]{2}{*}{ Number of abortion done before } & One time & 89 & 45.9 \\
\hline & Two times & 28 & 14.4 \\
\hline \multirow{2}{*}{ Is the pregnancy is wanted } & Yes & 119 & 61.3 \\
\hline & No & 75 & 38.7 \\
\hline \multirow{5}{*}{ Reason for termination } & Financial reason & 83 & 42.8 \\
\hline & Health reason & 32 & 16.5 \\
\hline & Partner pressure & 19 & 9.8 \\
\hline & Close pregnancies & 14 & 7.2 \\
\hline & Complete education & 46 & 23.7 \\
\hline \multirow{3}{*}{ Method used (abortion methoed) } & Plastic & 55 & 28.4 \\
\hline & Metal & 36 & 18.6 \\
\hline & Medication & 103 & 53.1 \\
\hline \multirow{4}{*}{ Fertility return after abortion } & Only once & 44 & 27.7 \\
\hline & Twice & 19 & 9.8 \\
\hline & Three times & 4 & 2.1 \\
\hline & More than three times & 4 & 2.1 \\
\hline \multirow{3}{*}{ Do you have a plan for pregnancy } & Never & 98 & 50.5 \\
\hline & Yes (within 3 months) & 9 & 4.6 \\
\hline & Yes (within two years) & 85 & 43.8 \\
\hline \multirow{2}{*}{ Sex of who assisted by } & Male & 118 & 60.8 \\
\hline & Female & 76 & 39.2 \\
\hline \multirow{3}{*}{ The patients were assisted by } & Physician & 45 & 23.2 \\
\hline & Nurse/midwifes & 64 & 33.0 \\
\hline & Do not know the designation & 85 & 43.8 \\
\hline \multirow{2}{*}{ Information FP Provide } & Yes & 188 & 96.9 \\
\hline & No & 6 & 3.1 \\
\hline \multirow{2}{*}{ FP Method provided } & Yes & 186 & 95.9 \\
\hline & No & 7 & 3.6 \\
\hline \multirow{6}{*}{ Method provided } & Oral Contraceptive (COC) & 67 & 34.5 \\
\hline & Injectable & 79 & 40.7 \\
\hline & Implant & 29 & 14.9 \\
\hline & IUD & 8 & 4.1 \\
\hline & Condom & 9 & 4.6 \\
\hline & Natural method & 2 & 1.0 \\
\hline
\end{tabular}




\subsection{The Magnitude of Client Satisfaction in the Quality of Post-abortion Care}

Among 194 interviewed clients, about 169 (87.1\%, 95\% CI: $(82,91.8))$ participants were satisfied with the quality of PAC care services given in the health facilities (Figure 1).

About 193 (99.5\%) participants said that the providers listened and responded to their questions very well and they gave them a chance to discuss any questions which they want to ask. More than half of the respondents, 134 (69.1\%) reported that they were treated with politeness and respect. About $117(60.3 \%)$ said that the provider listens to their concerns, $186(95.9 \%)$ reported that the health care provider addressed all of their questions, $142(73.2 \%)$ reported they feel and received the information and services that they wanted to get, about $166(85.6 \%)$ participants reported that the treatment procedure was verified by the health care provider before the procedure begin., About 147 (75.4\%) participants reported that the health care provider explains the procedures before they were performed, and $190(97.9 \%)$ said that the provider explained the results of the examination.

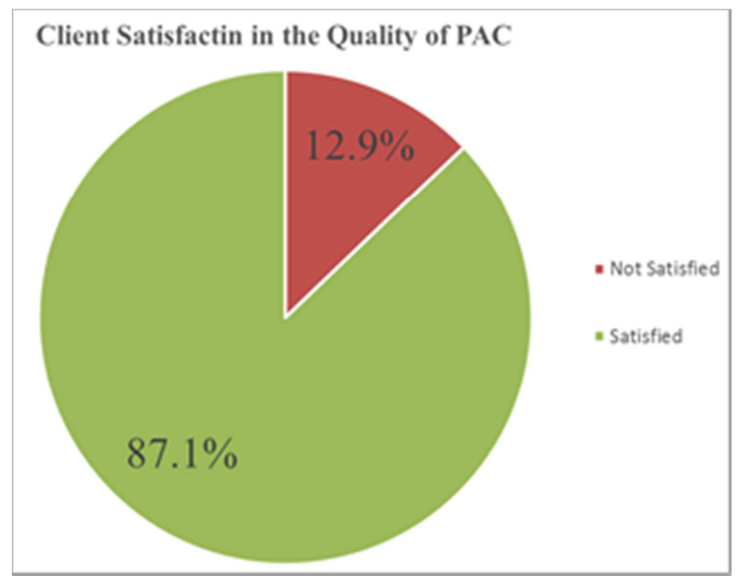

Figure 1. Magnitude of client satisfaction in the quality of post-abortion care among service users in public health facility of Gambella town, Ethiopia, $2019(N=194)$.

Table 3. Post-abortion care and client-provider interaction and other related characteristics among post-abortion clients in Gambella town, Ethiopia (N=194) in Gambella, Ethiopia, 2019.

\begin{tabular}{|c|c|c|c|}
\hline Variables & Category & Frequency & Percent \\
\hline \multirow{2}{*}{ Treated politely and Respectfully during your stay in this hospital } & Yes & 60 & 30.9 \\
\hline & No & 134 & 69.1 \\
\hline \multirow{2}{*}{ Did you have any concerns you wanted to discuss with the provider } & Yes & 193 & 99.5 \\
\hline & No & 1 & .5 \\
\hline \multirow{2}{*}{ Did the provider listens to your idea } & Yes & 117 & 60.3 \\
\hline & No & 77 & 39.7 \\
\hline \multirow{2}{*}{ Did the provider respond to all your questions that you raised } & Yes & 186 & 95.9 \\
\hline & No & 8 & 4.1 \\
\hline \multirow{2}{*}{ Do you feel that you received the information and services that you wanted } & Yes & 142 & 73.2 \\
\hline & No & 52 & 26.8 \\
\hline \multirow{2}{*}{ Before your treatment, did the health professional talk to you about the } & Yes & 166 & 85.6 \\
\hline & No & 28 & 14.4 \\
\hline \multirow{2}{*}{ Did the provider conduct health examinations or procedures } & Yes & 127 & 65.5 \\
\hline & No & 66 & 34.0 \\
\hline \multirow{2}{*}{ Provider explains the procedures before they begin } & Yes & 67 & 40.9 \\
\hline & No & 127 & 59.1 \\
\hline \multirow{2}{*}{ Provider explains the results of the health examinations } & Yes & 190 & 97.9 \\
\hline & No & 4 & 2.1 \\
\hline \multirow{3}{*}{ Did the provider tell you danger signs/ that may necessitate revisiting } & Yes & 172 & 88.7 \\
\hline & No & 15 & 7.7 \\
\hline & I do not know & 7 & 3.6 \\
\hline \multirow{3}{*}{ Did you take any brochure or educational material to bring home } & Yes & 154 & 79.4 \\
\hline & No & 38 & 19.6 \\
\hline & I do not know & 2 & 1.0 \\
\hline \multirow{5}{*}{ The subject of the material that you bring it } & FP & 40 & 20.6 \\
\hline & Antenatal/Postnatal & 100 & 51.5 \\
\hline & Delivery service & 4 & 2.1 \\
\hline & Abortion & 31 & 16.0 \\
\hline & other & 19 & 9.8 \\
\hline \multirow{2}{*}{ Offered any antipain medication during the procedure } & Yes & 127 & 65.5 \\
\hline & No & 67 & 34.5 \\
\hline \multirow{2}{*}{ The service provider tells you when to come back for another visit } & Yes & 157 & 80.9 \\
\hline & No & 37 & 19.1 \\
\hline \multirow{2}{*}{ Receiving the services you came for was reasonable or too long } & Reasonable & 68 & 35.1 \\
\hline & Too long & 126 & 64.9 \\
\hline \multirow{2}{*}{ Did you received the contraceptive method during this visit } & Yes & 179 & 92.3 \\
\hline & No & 15 & 7.7 \\
\hline
\end{tabular}


Post-abortion Service and Other related characteristics

About $126(64.9 \%)$ of the clients responded that the time spending in the facility beginning from arrival was fair and satisfactory. Regarding the family planning issues, about $17692.3 \%$ ) of participants reported that they get the contraceptive method which they want to be based on their interest at the time of discharge. About the post-abortion concealing, about $172(88.7 \%)$ participants reported that they received information on current illness, a danger sign, and about $15(7.7 \%)$ of the cases were not informed about danger signs that may necessitate revisiting the facilities (Table 3).

Table 4. Factors independently associated with satisfaction of clients on post-abortion care in public health facilities of Gambella town, southwest Ethiopia, 2019.

\begin{tabular}{|c|c|c|c|c|c|}
\hline \multirow{2}{*}{ Variables } & \multirow{2}{*}{ Category } & \multicolumn{2}{|c|}{ Satisfaction } & \multirow{2}{*}{ COR (95\% CI) } & \multirow{2}{*}{ AOR (95\% CI) } \\
\hline & & No $(\%)$ & Yes $(\%)$ & & \\
\hline \multirow{3}{*}{ Marital Status } & Married & $12(9.4)$ & $115(90.6)$ & 1 & 1 \\
\hline & Single & $8(24.2)$ & $25(75.8)$ & $9.5(3.90,23.5)$ & $1.41(0.53,3.7)$ \\
\hline & Others & $17(50)$ & $17(50)$ & $3(1.1,8.2)$ & $1.05(0.39,2.7)$ \\
\hline \multirow{3}{*}{ History of Abortion } & No & $9(11.7)$ & $68(88.3)$ & 1 & 1. \\
\hline & One times & $16(18)$ & $73(82)$ & $1.66(0.69,3.99)$ & $1.65(0.67,4.0)$ \\
\hline & $\geq 2$ times & $12(57)$ & $16(43)$ & $5.67(2.04,15.7)$ & $2.1(1.6,13.8)^{*}$ \\
\hline \multirow{2}{*}{ Pregnancy wanted } & Yes & $20(15)$ & $114(85)$ & 1 & 1 \\
\hline & No & $17(28.3)$ & $43(71.7)$ & $2.25(1.9,9.58)$ & $1.8(1.17,10.9)^{* *}$ \\
\hline \multirow{3}{*}{ The method used (abortion) } & MVA & $20(36.4)$ & $35(63.6)$ & $0.32(0.14,1.44)$ & $0.28(0.11,1.01)$ \\
\hline & $\mathrm{DC}$ & $6(16.7)$ & $30(83.3)$ & $0.92(0.2,1.2)$ & $0.11(0.02,0.95)$ \\
\hline & Medication & $16(15.5)$ & $87(84.5)$ & 1 & 1 \\
\hline \multirow{3}{*}{ Patient was assisted by } & Physician & $7(18)$ & $32(82)$ & $6.5(1.7,9.5)$ & $3.9(1.6,8.6)^{* *}$ \\
\hline & Nurse & $30(51.7)$ & $28(48.3)$ & $1.33(0.276,2.02)$, & $0.73(0.26,2.03)$ \\
\hline & Others & $57(58.8)$ & $40(41.2)$ & 1 & 1 \\
\hline \multirow{2}{*}{ Treated politely and respectfully } & Yes & $5(8.3)$ & $55(91.7)$ & $6.4(1.9,21.9)$ & $6.3(1.82,22.2)^{* *}$ \\
\hline & No & $34(25.4)$ & $100(74.6)$ & 1 & 1 \\
\hline \multirow{2}{*}{ Provider address all questions } & Yes & $5(6.5)$ & $72(93.5)$ & $5.42(2,14.64)$ & $5.1(1.9,14.5)^{* *}$ \\
\hline & No & $32(27.3)$ & $85(72.7)$ & 1 & 1 \\
\hline \multirow{2}{*}{ Explained the procedure } & Yes & $6(9.1)$ & $60(90.9)$ & $3.09(1.2,7.86)$ & $2.49(1.10,5.66)$ \\
\hline & No & $30(23.6)$ & $97(76.4)$ & 1 & 1 \\
\hline \multirow{2}{*}{ Receiving anti-pain } & Yes & $6(9)$ & $61(91)$ & $3.28(1.2,8.33)$ & $3.08(1.18,7.89)$ \\
\hline & No & $31(23.8)$ & $96(76.2)$ & 1 & 1 \\
\hline \multirow{2}{*}{ Facility waiting time } & Reasonable & $7(10.3)$ & $61(89.7)$ & $2.72(1.2,6.5)$ & $2.5(1.03,6.20)$ \\
\hline & Too long & $30(23.9)$ & $96(76.1)$ & 1 & 1 \\
\hline
\end{tabular}

$*=\mathrm{p}$-value $<0,05 ; * *=\mathrm{p}$-value $<0,01 ; \mathrm{AOR}=$ adjusted odds ratio; $\mathrm{COR}=$ Crud odds ratio; $\mathrm{CI}=\mathrm{Confidence} \mathrm{interval}$

\subsection{Factors Associated with Client Satisfaction in the Quality of Post-abortion Care}

In the binary logistic regression, those who were single, history of abortion, unwanted pregnants, manual vacuum aspiration (MVA) method used, assisted by a physician, treated them politely and respectfully, care provider listens and address their questions, clearly announcing the producer, and receiving medication (antipain) were significantly associated factors. However, in the final model (multivariable analysis), Unwanted, history of abortion, assisted by a physician, treated politely and respectfully, the provider address all questions were significantly associated factors (Table 4).

\section{Discussion}

Overall, about $169 \quad(87.1 \%, \quad 95 \% \quad$ CI: $\quad(82,91.8))$ participants were satisfied with the quality of PAC services. Unwanted pregnancy, history of abortion, assisted by a physician, Provider address of all questions, and being treated politely and respectfully were significantly associated factors.

The result in this study $(87.1 \%)$ is in line with the finding from Guragea 83.5\% [23]. The possible reason for the similarity could be due to the similarity in the study subjects and the similarity of socio-demographic and culture of the study subjects in both studies. But the finding is higher than the findings from Mexico 24\%, Tanzania (20\%), in Tigray (40.6\%), in Oromia and Amhara region (79.6\%), Jimma (76.3\%), and Adis Ababa (60.5\%) [25-30]. The possible reason for the discrepancy might be due to the variation in the sample size, study subjects, sampling methods, and sociocultural and demographic background of the study subjects.

In this study, about $69.1 \%$ reported that they were treated with politeness and respect. This is similar to studies in Mexico (83\%), and Guragea (93.5\%) [23, 26]. About 92.3\% of participants in this study reported that they received the contraceptive method which they want in their interest and were counseled about the family planning services at the time of discharge. This is supported with findings done in Oromia 
and Amhara region in which $53.4 \%$ left the health facility by concealing about family planning and $44 \%$ received appropriate information and returned with different contraception methods [29]. This is also supported by a study in Guragea in which about $56.5 \%$ and in Tigray about $48 \%$ of participants were received accurate information and postabortion family planning $[23,28]$.

This study tried to assess associate factors. Unwanted pregnants were 1.8 times more likely satisfied compared with wanted pregnants. The possible reason might be the pregnancy is not wanted there may be other problems like the pregnancy may be due to sexual violence. Whatever the case terminating the pregnancy may make them happy for those unwanted pregnants this could increase their satisfaction.

Those participants reported that the health care provider who treated them politely and respected manner were 6.3 times more satisfied compared to the counterparts. This is consistent with the study done in Mexico [26]. The possible explanation might be in health psychological treatment plays a major role in client-provider interaction. This might increase the satisfaction of the clients.

Those whose women had a history of abortion two and above times were 2.1 times more satisfied than those who had no history of abortion. This is consistent with the study done in Jimma [30]. The possible reason for this might be due to those who had history had exposed to the abortion process, whereas those who had not history were everything become new for them.

Participants who were assisted by physicians were 3.9 times more satisfied with the quality of PAC service compared to those who were assisted by other health care providers. This is supported by the study done in Mexico, and America [26, 31]. The possible explanation for this might be due to the community's perception of the doctors. Even though an abortion can be done by any trained health care provider some communities may give high priority to the physicians than other health care providers.

Participants who reported the health care provider address all information were 5.1 times more satisfied compared to those who reported provider did not address all information. This is supported by a study done in Mexico [26]. The reason might be due to those who received the whole information they need may not have complained and clearly understand which may increase the satisfaction.

Those who reported providers were listened to and addressed the information were 6.3 times more satisfied as compared to those who report they did not address the information. This is consistent with the study done in America and Jimma [30, 31]. The reason might be due to if the health care provider says well come in a respected and treated manner they believe him/her and provide the necessary information without hiding. If the interaction between the health care provider and the client is good it may increase their satisfaction.

Limitations

There might be social desirability bias and the sampling method was a consecutive method which is a non-probability sampling technique that is not generalizable for the whole population.

\section{Conclusion}

Overall, about $87.1 \%$ of the participants were satisfied with the quality of PAC services in this study. The majority of the participants were satisfied with the quality of PAC services. Bing unwanted pregnancy, history of abortion, assisted by a physician, being treated politely and respectfully, and the provider listens and addresses all information were significantly associated factors. Enhancing client centered care in the facility, strengthening awareness of family planning services, and addressing the questions of the clients in a respected manner in all health facility by all health care providers are important measures that increase client satisfaction.

\section{Abbreviations}

COC: Combined oral contraceptive

CPR: Contraceptive prevalence rate

FP: Family Planning

IUCD: Intrauterine contraceptive method

MVA: Manual Vacuum aspiration

PAC: Post abortion care

SSA: sub-Saharan Africa

WHO: World Health Organization

\section{Data Sharing Statement}

The data used for the findings of this study are available from the corresponding author upon reasonable request.

\section{Ethical Approval}

Ethical clearance was secured from Metu University Institutional Health Research Ethics Review Committee (IHRERC) and official permission was obtained from Gambella Health Bureau and each public hospital. Voluntary, written, informed, and signed were obtained from each study participant.

\section{Funding}

No fund to report

\section{Author Contributions}

Both authors made substantial contributions to conception and design, acquisition of data, or analysis and interpretation of data; took part in drafting the article or revising it critically for important intellectual content; agreed to submit to the current journal; gave final approval of the version to be published, and agree to be accountable for all aspects of the work. 


\section{Disclosure}

The authors declare that they have no conflicts of interest in this work.

\section{Acknowledgements}

We would like to appreciate Metu University. Our heartfelt thanks also extend to supervisors, data collectors, and the study participants for their willingness and cooperation in the data collection process.

\section{References}

[1] Centre for Development and Population Activities 1400 16th Street NW, Suite 100, Washington, DC 20036 USA. A Guide to Providing Abortion Care.

[2] Pascoe GC. Patient satisfaction in primary health care: a literature review and analysis. Eval Prog Plan: 6.1983; 185210.

[3] Elisabeth A, Iqbal S: Unsafe abortion, Global and regional estimates of the incidence of unsafe abortion and associated mortality in 2000. Fourth edition. Geneva, Switzerland: WHO; 2004: 14-15.

[4] Osur J, Baird TL, Levandowski BA, Jackson E, Murokora D. Implementation of misoprostol for postabortion care in Kenya and Uganda: A qualitative evaluation. Glob Health Action. 2013; 6: 1-11.

[5] Hassen F: Analysis of factors for unwanted pregnancy among women in the reproductive age group attending health institutions in Jimma Town. 2000: 136-138.

[6] Gerdts C, Prata N, Gessessew A (2012) an unequal burden: risk factors for severe complications following an unsafe abortion in Tigray, Ethiopia. Int J Gynaecol Obstet: 118 Suppl 2: S107-112.

[7] World Health Organization. Unsafe Abortion: Global and Regional Estimates of the Incidence of Unsafe Abortion and Associated Mortality in 2008. Geneva: World Health Organization; 2011.

[8] Say L, Chou D, Gemmill A, et al. Global causes of maternal death: A WHO systematic analysis. Lancet Glob Health. 2014; 2: e323-e333.

[9] Thiam FT, Suh S. Scaling Up Postabortion Care Services: Results from Senegal. 2006; 5 (5): 1-27.

[10] United Nations Expert Group Meeting For The Review And Appraisal Of Population And Development And Its Contribution To The Follow-Up And. 2018: 1-6.

[11] Otsea K, Benson J, Alemayehu T, Pearson E, Healy J. Testing the Safe Abortion Care model in Ethiopia to monitor service availability, use, and quality. Int J Gynaecol Obstet: 2011: 115: 316-321.

[12] Johnston HB, Akhter S, Oliveras E. Quality and efficiency of care for complications of unsafe abortion: A case study from Bangladesh. Int J Gynecol Obstet. 2012; 118 (Suppl. 2): 141-147.

[13] Client Satisfaction with Abortion Services at the National
Women's Hospital Pereira Rossell in Montevideo, Uruguay.

[14] Adinma JI, Ikeako L, Adinma ED, Ezeama CO, Ugboaja JO. Awareness and practice of post-abortion care services among health care professionals in southeastern Nigeria. Southeast Asian J Trop Med Public Health: 2010: 41: 696-704.

[15] Vlassoff M, Walker D, Shearer J, Newlands D, Singh S. Estimates of health care system costs of unsafe abortion in Africa and Latin America. Int Perspect Sex Reprod Health: 2009 35: 114-121.

[16] Shearer JC, Walker DG, Vlassoff M. Costs of post-abortion care in low- and middle-income countries. Int J Gynaecol Obstet: 2010: 108: 165-169.

[17] National Guidelines on Post Abortion Care National Guidelines on Post Abortion Care. 2014.

[18] Prada E, Kestler E, Sten C, Dauphinee L, Ramirez L. Abortion, and Postabortion Care in Guatemala: A Report from Health Care Professionals and Health Facilities. New York: Guttmacher Institute; 2005.

[19] Rasch V, Yambesi F, Massawe S. Medium and long-term adherence to post-abortion contraception among women having experienced unsafe abortion in Dar es Salaam, Tanzania. BMC Pregnancy Childbirth. 2008; 8: 32-39.

[20] Okonofua FE, Hammed A, Nzeribe E, et al. Perceptions of policymakers in Nigeria toward unsafe abortion and maternal mortality. Int Perspect Sex Reprod Health. 2009; 35: 194-202.

[21] Postabortion Care Consortium Community Task Force. Essential elements of postabortion care: An expanded and updated model. Postabortion Care Consortium, July 2002.

[22] Gambella Regional Health Bureau Estimated annual report 2018.

[23] Tesfaye G, Oljira L. Post-abortion care quality status in health facilities of Guraghe zone, Ethiopia. Reprod Health. 2013: 10: 35 .

[24] WHO: Unsafe abortion Global and regional estimates of the incidence of unsafe abortion and associated mortality. Sixth edition. Geneva, Switzerland: WHO; 2008: 2-31.

[25] Tadele Kasie, Geteneh Moges Assefa, Ahimed Ali, and Worku Tefera. Magnitude and factors associated with unintended pregnancy among pregnant women in Addis Ababa, Ethiopia. 2017; 6 (4).

[26] Davida Becker, Claudia Díaz- Olavarrieta, Clara Juárez, Sandra G. García, Patricio Sanhueza, and Cynthia C. Harper. Clients' Perceptions of the Quality of Care in Mexico City's Public-Sector Legal Abortion Program. International Perspectives on Sexual and Reproductive Health, 2011, 37 (4) 191-201.

[27] Baynes C, Yegon E, Lusiola G, Kahando R, Ngadaya E, Kahwa J. Women's satisfaction with and perceptions of the quality of postabortion care at public-sector facilities in mainland Tanzania and Zanzibar. Glob Health Sci Pract. 2019; 7: S299-S314.

[28] Demtsu B, Gessessew B, Alemu A. Assessment of Quality and Determinant Factors of Post-Abortion Care in Governmental Hospitals of Tigray, Ethiopia, 2013. Family Medicine and Medical Science Research: 3: 140. doi: 10.4172/2327-4972.1000140. 
[29] Solomon Kumbi, Yilma Melkamu, Hailu Yeneneh. Quality of post-abortion care in public health facilities in Ethiopia. Ethiop. J. Health Dev. 2008; 22 (1): 26-33.

[30] Sena Belina Kitila, and Fekadu Yadassa. Client Satisfaction with Abortion Service and Associated Factors among Clients Visiting Health Facilities in Jimma Town, Jimma, South West, Ethiopia. Quality in Primary Care (2016) 24 (2): 67-76.
[31] Justine P. Wu; Emily M. Godfrey; Linda Prine; Kathryn L. Andersen,; Honor MacNaughton; Marji Gold, Women's Satisfaction With Abortion Care in Academic Family Medicine Centers in America. Fam Med: 2015; 47 (2): 98-106. 